\title{
Influence of Investor Sentiments on Stock Market Capitalization of Different Economic Sectors in a Developing Economy: Evidence from Pakistan
}

\author{
Syed Ali Raza * $\quad$ Muhammad Mansoor $^{\dagger} \quad$ Khalid M. Iraqi ${ }^{\ddagger}$
}

\begin{abstract}
This study investigates the effect of investor sentiment on the stock market capitalization on different economic sectors of Karachi Stock Exchange of Pakistan by using the data from the year 19722014. The findings of EGARCH model suggest that the Power and Fuel sector and the Chemical sector are more affected by investor sentiment as compared to the other sectors due to the presence of big giants' firms of Pakistani market in those sectors. Furthermore, it is concluded that noise traders are irrational traders and they follow news and trends. Therefore, it is recommended that a number of different educational and awareness programs should be introduced for the individual investors to make them financial literate, and through this process the number of knowledgeable investors can be increased and the impact of noise traders can be reduced.
\end{abstract}

Keywords: Investor sentiment, different sectors, noise traders, market capitalization, behavioral finance.

\section{Introduction}

For many years' statisticians, economists, and different scholars have been involved in developing and testing diverse models which can predict the movement in stock markets. Some researchers try to use the information of past behavior of stocks to predict the tenable future, others use stock index to predict the movement, but it remains a big question that which model is best to predict the volatility of the stock market. Stock market refers to a place where shares of publicly held companies are traded. It provides an opportunity for the general public to grow a small amount of money into large ones and, on the other hand, it also offers companies to raise capital in exchange for giving investors a piece of ownership in the company.

A number of different factors are responsible for the movement of stock prices which may include inflation, unemployment, foreign direct investment, workers' remittances, interest rate, gross domestic product, money supply, wholesale price index and many more (Raza \& Jawaid, 2014; Raza, 2015; Raza, Jawaid, Afshan, \& Karim, 2015). Researchers have found a relatively newer variable which may cause move in the stock

\footnotetext{
*Department of Management Sciences, IQRA University, Karachi, Pakistan. Email: syed_aliraza@hotmail.com

† Department of Management Sciences, IQRA University, Karachi, Pakistan. Email: iu.mansoor@gmail.com

${ }^{\ddagger}$ Department of Public Administration, University of Karachi, Karachi, Pakistan.
} 
market i.e. Investor sentiment, which is often referred as market sentiment, is basically a feeling or psychology of an investor towards any particular stock. It is an overall attitude of the investor regarding any specific company which may be exposed when the stocks are traded in the market or if there is a sudden movement of prices. Investor sentiment is one of the most significant content of the theory of behavioral finance.

It must be noted that the significance of the stock market is growing day by day and the worth of investors also increases. Traditional financial theories focus only on the importance of rational investors, thus neglecting human psychology and feelings while making any decision of buying and selling of stocks. Behavioral finance has emerged as one of the most important topic of discussion, and some more weight is given to the investor psychology and feelings which can cause movement in the stock market. Now the researchers are of the view that not only the macroeconomic factors affect the price of stocks, but there are investor sentiments which do affect the stock prices. They are responsible for pressing the prices upward and downward. These sentiments don't follow fundamental knowledge or data rather they rely on general market information or they may follow certain trends.

Stock market of Pakistan is an emerging one and recently it regained the status of "tiger" in the Asian region which was lost in 2008. The last economic year was comparatively better for Pakistan Stock Exchange and KSE100 index demonstrated an overall positive performance during the period from July 2014 - June 2015. The landmark performance of the stock market during current fiscal year can be attributed to a number of positive factors including a stable macroeconomic environment, stable exchange rate, acceleration in the privatization process, downward inflation trend, and etc. The positive inclination of the index continued and touched all time high level of 34,826.51 points.

Many studies have been done in the recent years, which argue that how much an investor sentiment will affect the stock market. The studies on different stock exchanges of the countries like USA, Sayim, Morris, and Rahman (2013); Turkey, Uygur and Taş, (2014); India, China Hu and Wang (2013); Germany, Finter, Niessen-Ruenzi, and Ruenzi (2012), finds out a significant relationship between the stock market returns and investor sentiment. Hu and Wang (2013) concluded that the Chinese market is operated by highly speculative investors so it is largely influenced by investor sentiment. Finter et al. (2012) find out that bad news gets more attention and investors react stronger to that which is consistent with the findings of Li (2015) which investigates that the reaction of the stock market is more severe in an economic downturn than in the expansion phase.

Moreover, the stock market of Pakistan is very volatile and investors are themselves responsible to create the volatility due to lack of relevant knowledge and absence of statistical methods to predict the stock market volatility (Raza, Jawaid, Arif, \& Qazi, 2011). As it is a developing market, so it has to face these issues. So there is a need to fill the information gap in the Pakistani context that how significantly investor sentiment affects stock market, which is important for both, the investors and the industry analysts.

The need to fill this knowledge gap is essential today as people are more prone towards stock market to enjoy higher stock returns. The Government also wants that people invest more in the stock market than in the fixed deposits of banks, as they reduce the discount rate to $5.75 \%$ to encourage them to take risks. As people invest more in the 
stock market, it will eventually create a better economic picture of the country's economy and will attract the foreign investors to make large investments which in turn will create a boom in the overall economy. The foreign investors, who intend to invest in Pakistan, can also get benefited with this study as they will come to know about different economic sectors and the psyche and attitude of Pakistani investors.

Moreover, the stock market has gained momentum in the current fiscal year as it is continuously on the higher side. So it is more important now to identify the effect of investor sentiment on the stock market as it has extended its popularity. The objective of this research is to enhance the current knowledge of behavioral finance within the context of Pakistan and to explain the effect of investor sentiment on the stock market.

\section{Literature Review}

\section{Theoretical Background}

Many theories have been developed in the past which argued about the effect of investor sentiments on the stock market. Out of many some are described below:

A large number of noise traders are responsible for the volatility in the stock market due to their sentimental decision making. Noise trader can be defined as the people who respond to any non-information, or advice of brokers, or follow trends. These noise traders can have higher or predictive expectations as they follow the ups and downs of the market. On the other hand, the people who are rational investors, they efficiently employ new information and also possess rational expectations .

Malkiel (1991) states that when a market truly and properly reflects all the appropriate information necessary to determine stock prices is said to be efficient market. Formally, the market is said to be efficient with respect to any information set, if security prices would be unaffected by revealing that information to all participants. According to the efficient market hypothesis, stocks always trade at their fair value on stock exchanges, making it impossible for investors to either purchase undervalued stocks or sell stocks for inflated prices.

\section{Empirical Studies}

Different researchers in the recent past have tried to explore the relationship between investor sentiment and stock market or stock returns. A number of developed and developing countries have been taken by researchers to show the differences that how investor sentiment could affect stock market different type of markets. Finter et al. (2012) studied the impact of investor sentiment on German market. Peng, Lai, Chen, and Wei (2015) examined the relationship among investor sentiment, customer satisfaction and stock returns in the US market. Kholdy and Sohrabian (2014) evaluated the effect of institutional and individual sentiments on the US stock returns. Szu and Yang (2015) scrutinized the influence of individual investor sentiment on Taiwan's option prices. Uygur and Taş (2014) scrutinized the impact of investor sentiments on different economic sectors from 
Istanbul Stock Exchange (ISE). Qiang and Shu-e (2009) investigated the effect of investor sentiments on the returns of stock in the Chinese Stock Market. Lux (2011) scrutinized the relation between stock returns and sentiment dynamics in the German stock market. Simões Vieira (2011) examined how investor sentiment affects the market reaction to the dividend change announcement in the European context. Białkowski, Etebari, and Wisniewski (2012) observed the interrelationship between stock returns and investor sentiment during the month of Ramadan. Beaumont, van Daele, Frijns, Lehnert, and Muller (2008) investigates that how investor sentiment effect the conditional volatility and return process of the three major markets of the US.

\section{Emerging Markets and Investor Sentiment}

Li (2015) investigated the effect of investor sentiment on stock prices in China and finds out that the shocks which were caused by sentiment create far more variations than the other variables. Szu and Yang (2015) examined the influence on Taiwan's option prices by the individual's investor sentiments in the financial crises and the study concluded that Taiwan's stock index option prices were significantly influenced by the investor's expectations. Uygur and Taş (2014) scrutinized the impact of investor sentiments on different economic sectors from Istanbul Stock Exchange (ISE) and the findings of the study suggested that the change in investor sentiment has more influence on conditional volatility of industry, beverages, banking and food sector indexes when compared with other sectors such as telecommunication or retail. Hu and Wang (2013) investigated the impact of noise trading on stock returns in Chinese market and the findings suggested that the investor sentiment significantly influences small and large-cap stocks as the retail investors are highly speculative. Qiang and Shu-e (2009) investigated the effect of investor sentiments on the returns of stock in the Chinese Stock Market and the result of the study shows that the investor sentiments have a significant effect on the prices of stocks. Furthermore, the results also revealed that the positive changes in investor's sentiment have more effect on the prices of stocks than the negative ones.

\section{Developed Markets and Investor Sentiment}

Sayim et al. (2013) inspect the effect of USA individual investor sentiments on particular industry's stock return and volatility and finds out that result shows that the individual investor sentiment is positively related to the premium on a portfolio of small stocks relative to large stocks. Finter et al. (2012) finds out that investor sentiment has low influence in forecasting future returns, the reason for this low power could be because the German market consists of sophisticated investors who relies less on the sentiments. Lux (2011) scrutinized the relation between stock returns and sentiment dynamics in the German stock market and finds out that results shows causal relation from sentiment to stocks, the outcome of the trading experiments are quite disappointing and diffuse. Simões Vieira (2011) examined how investor sentiment affects the market reaction to the dividend change announcement in the European context and finds out that the study concludes that two markets out of three i.e. UK and French market were affected by in- 
vestor sentiment when the news of dividend change was announced in the market and the Portuguese market was found to be unresponsive.

\section{Data and Methodology}

R. Engle (2001) suggested that data suffers from heteroscedasticity when the variance of the error terms is not equal causing the error terms to be fairly larger for some points or ranges of the data than for others. It would be insufficient to use an ordinary autoregressive method such as ARMA to model non-constant conditional variances with heteroscedasticity present in the data because the standard errors and confidence intervals computed by standard methods would be too narrow, although the coefficients for an ordinary least squares regression are still unbiased. In $\mathrm{ARCH}$ and GARCH models, heteroscedasticity is considered as a variance to be modelled instead of as a problem. The equation of the generalized GARCH model for the variance is seen as below as the variance of the residuals of a regression

$$
\begin{gathered}
r 1=m_{t}+\sqrt{h_{t} \epsilon_{t}} \text { is denoted as } h_{t} \\
h_{t+1}=\omega+\alpha\left(r_{t}-m_{t}\right)^{2}+\beta h_{t}=\omega+\alpha h_{t} \epsilon_{t}^{2}+\beta h_{t}
\end{gathered}
$$

Where the constant $\omega$, and the coefficients $\alpha, \beta$ are to be forecasted. The above GARCH model is typically called GARCH (1.1). The first number in the parentheses refers to how many autoregressive lags, or ARCH terms exist in the equation, whereas the second term refers to how many moving average lags are specified which is called the number of GARCH terms. The ARCH mechanisms are modelled by R. F. Engle (1982) as serially uncorrelated processes with non-constant variances conditional on the past, but constant unconditional variances. R. F. Engle (1982) suggested in the first ARCH model that the conditional variance is a function of past squared returns, whereas Bollerslev (1986) proposed and used further dependencies in the equation of conditional variance in GARCH models. Nelson (1991), on the other hand, constructed conditional variance in logarithmic form in the EGARCH model where there are no constraints for non-negativity of the coefficients. A negative shock leads to a higher conditional variance in the following period than a positive shock in EGARCH models. Lee, Jiang, and Indro (2002) has used Investors' Intelligence Index as a proxy for investor sentiment and proposed a GARCH-M model which has simultaneous changes in investor sentiment in the mean equation and lagged changes in the magnitude of investor sentiment in the variance equation. Verma and Verma (2007), on the other hand, have used an E-GARCH model and AAII investor sentiment as a proxy. The study of Wang, Li, and Lin (2009) is one of the recent works that uses GARCH methodology where GJR-GARCH, EGB2 and SWARCH methods are used in order to assess the effects of investor sentiment on the Taiwan Futures Exchange. The GJR-GARCH model to test the asymmetric effects of the sentiment is as follows:

$$
\mu_{t}=\theta_{0}+\theta_{1} h_{t}+\theta_{2} \Delta S I_{t}+\epsilon_{t}
$$




$$
h_{t}=\gamma_{0}+\gamma_{1} \epsilon_{t-1}^{2}+\gamma_{2} \epsilon_{t-1}^{2} I_{t-1}+\gamma_{3} h_{t-1}+\gamma_{4} R_{f}+\gamma_{5}\left(\Delta S I_{t-1}\right)^{2} D_{t-1}+\gamma_{6}\left(\Delta S I_{t-1}\right)^{2}\left(1-D_{t-1}\right)
$$

Another recent study of Yu and Yuan (2010) has demonstrated the investor sentiment has a considerable effect on the mean, variance trade-off using GARCH $(1,1)$ and asymmetric GARCH $(1,1)$.

The main purpose of this paper is to formulate a model to evaluate the adverse effects of investor sentiment on different kind of sector indexes in Karachi Stock Exchange (KSE). Yearly market capitalization data of Karachi Stock Exchange (KSE) of sector indexes of KSE from the year 1972-2014 are used in the study. Instead of using survey data or other sentiment indexes, a new sentiment proxy is formed in order to capture the effects of investor sentiment on the market capitalization and conditional volatility of stock markets. Yearly market capitalization is the most suitable and practical investor sentiment proxy that could be employed with a study focusing on Karachi Stock Exchange due to unavailability of other measures. An EGARCH model is suggested in this study for overcoming the non-negativity constraints and understanding the asymmetric effects more clearly.

$$
\mu_{t}=\theta_{0}+\epsilon_{t}
$$

Where,

$\mu_{t}$ is the value of the market capitalization of the particular sector,

$\theta_{0}$ constant term,

$\epsilon_{t}$ is the Error Term

$$
\log \left(h_{t-1}\right)=\gamma_{0}+\gamma_{1}\left[\left|\epsilon_{t-1}\right| / \sigma_{t-1}-\sqrt{2 / \pi}\right]+\gamma_{2}\left(\epsilon_{t-1} / \sigma_{t-1}\right) \gamma_{3} h_{t-1}+\gamma_{4} \Lambda \text { Sent }_{t-1}
$$

Where,

$h_{t}$ the market's conditional volatility

$\epsilon_{t-1}$ is the first order autoregressive lag term.

$\gamma_{2}$ is the demonstrates the effect of negative innovations to market capitalization,

$\gamma_{3}$ is the persistence of volatility,

$\gamma_{4}$ is the effect of change in investor sentiment.

Yearly market capitalization data of Karachi Stock Exchange (KSE) is employed as the substitute for investor sentiment. Since the variations in the market capitalization are not the sole indicators of noise trade behavior, but also the outcomes of many different macroeconomic events, market capitalization data are not directly used as a substitute for investor sentiment. Yearly market capitalization is regressed beside some macroeconomic variables; Gross Domestic Product (GDP), Whole Sale Price Index, Money Supply (M2), Consumers Price Index (CPI), and Discount Rate (DR). The residuals of the analysis are used as a measure of investor sentiment, which control the effects of macro-economic occasions on the noise trade behavior.

Yearly market capitalization of six different sectors of KSE from the year 1972-2014 is used as dependent variables in the EGARCH model. In the mean equation, $\mu_{1}$ is the 
value of the market capitalization of the particular sector and the constant term is $\theta_{0}$. In the equation of variance, the market's conditional volatility is denoted by ht, the first order autoregressive lag term is represented by $\epsilon_{t-1}$, while the change in investor sentiment controlled for macroeconomic variable is symbolized by $\beta$ Sent $_{t}$. The coefficient of $\gamma_{2}$ demonstrates the effect of negative innovations to market capitalization, while the $\gamma_{3}$ illustrates the persistence of volatility. $\gamma_{4}$ coefficient indicates the effect of change in investor sentiment on the particular KSE sector's market capitalization conditional variance. De Long, Shleifer, Summers, and Waldmann (1990) as cited in Uygur and Taş (2014) said that it possible $\gamma_{4}$ to be significant and positive because a rise in investor sentiment shows higher contribution of noise traders as their continuous selling and buying will increase the price volatility which is in line with the noise trader theory.

The main concern of this research is to check whether a hike in investor sentiment causes a greater increase the conditional variance of the stocks in particular economic sectors. The regarding coefficient $\left(\gamma_{4}\right)$ is reported and compared among each KSE sector index in order to understand whether the effect of the investor sentiment on conditional volatility differs for various sector indexes.

\section{Findings and Discussion}

The main interest of this study is to examine the relationship between investor sentiment and different sectors of the stock market. The study applied different tests to check the authenticity of the data. The Table 1 shows the descriptive statistics of the gathered data.

\begin{tabular}{|c|c|c|c|c|c|c|c|}
\hline & $\mathrm{CH}$ & CM & FI & FP & IS & PF & $\mathrm{TX}$ \\
\hline Mean & 105711 & 43964.04 & 93613.65 & 54103.96 & $-7.93 \mathrm{E}-10$ & 302542.8 & 50602.28 \\
\hline Median & 43759.9 & 7990 & 5437.2 & 4189.6 & -0.008 & 36830.1 & 27432.9 \\
\hline Maximum & 732856 & 353968 & 1468232 & 742219 & 0.723 & 1600417 & 347967 \\
\hline Minimum & 289.5 & 305.8 & 107.7 & 311 & -0.88 & 428.2 & 966.5 \\
\hline Std. Dev. & 164009.8 & 74231.11 & 274281.5 & 165391 & 0.388 & 484327.9 & 72043.94 \\
\hline Skewness & 2.000959 & 2.301 & 3.817759 & 3.418951 & -0.314 & 1.31174 & 2.299611 \\
\hline Kurtosis & 6.790466 & 8.635 & 17.49827 & 13.55965 & 2.758 & 3.043839 & 9.023034 \\
\hline Jarque-Bera & 54.43617 & 94.858 & 481.0644 & 283.5546 & 0.814 & 12.33486 & 102.895 \\
\hline Probability & 0.000 & 0.000 & 0.000 & 0.000 & 0.665 & 0.002097 & 0.000 \\
\hline Sum & 4545573 & 1890454 & 4025387 & 2326470 & $-3.41 \mathrm{E}-08$ & 13009342 & 2175898 \\
\hline Sum Sq. Dev. & $1.13 \mathrm{E}+12$ & $2.31 \mathrm{E}+11$ & $3.16 \mathrm{E}+12$ & $1.15 \mathrm{E}+12$ & 6.336 & $9.85 \mathrm{E}+12$ & $2.18 \mathrm{E}+11$ \\
\hline Observations & 43 & 43 & 43 & 43 & 43 & 43 & 43 \\
\hline
\end{tabular}

There are 43 observations of each sector. The power and fuel sector has the highest mean which is $302,542.8$ and Textile sector has the lowest mean i.e. 50,602.28. The highest value of sum lies in power and fuel, which is 13,009,342 while the lowest sum lies in the Construction and Material sector i.e. 1,890,454. The value of skewness of all the sectors is greater than 1 which shows that the skewness is substantial and the distribution is far from symmetrical.

To find out some structural breaks in the series, stationary analysis is executed through unit root test. In the series, there are high chances of existing of certain trend which may be 
because of certain outer occasions in the country or might be because of instable economy or unsound political conditions which might have incurred in the years which are taken in the study. The unit root test was performed at two points; firstly, at level and secondly at first different for all the variables in the study. The Table 2 shows the result of Unit root tests.

\begin{tabular}{|c|c|c|c|c|}
\hline \multirow[t]{3}{*}{ Variables } & \multicolumn{4}{|c|}{ ADF test statistics } \\
\hline & \multicolumn{2}{|c|}{$\mathrm{I}(0)$} & \multicolumn{2}{|c|}{ I(1) } \\
\hline & C & C \& T & C & C\&T \\
\hline CPI & 0.559 & 0.592 & 0.000 & 0.000 \\
\hline DR & 0.198 & 0.347 & 0.000 & 0.002 \\
\hline GDP & 0.380 & 0.930 & 0.001 & 0.002 \\
\hline MC & 0.998 & 0.993 & 0.011 & 0.009 \\
\hline MS & 0.114 & 0.224 & 0.000 & 0.000 \\
\hline WPI & 0.706 & 0.728 & 0.000 & 0.000 \\
\hline
\end{tabular}

The null hypothesis (Ho; Series is not-stationary) of the stationary analysis has been accepted at level for all the six variables of the study on the basis of ADF test. At the First difference, the null hypothesis (Ho; Series is not-stationary) of the stationary analysis has been rejected for all the six variables.

Furthermore, the co-integration test was also applied which shows whether the relationship between the variables is for longer time or not. And the claim is that there is no co-integration. According to the Table 3, the claim is rejected and the alternative is accepted. Therefore, according to the results there are five co-integration equations found from lag 0 to lag 4 between the variables. The result justifies that there is a long term relationship among the examined variables.

\begin{tabular}{lcccc}
$\begin{array}{l}\text { Table } 3 \\
\text { Results of cointegration analysis }\end{array}$ & & \\
\hline $\begin{array}{l}\text { Hypothesized } \\
\text { No. of CE(s) }\end{array}$ & $\begin{array}{c}\text { Trace } \\
\text { Statistic }\end{array}$ & $\begin{array}{c}\mathbf{5 \%} \\
\text { Critical Value }\end{array}$ & $\begin{array}{c}\text { Max. Eigen } \\
\text { value statistics }\end{array}$ & $\begin{array}{c}\mathbf{5 \%} \\
\text { Critical Value }\end{array}$ \\
\hline None * $^{*}$ & 273.4 & 117.7 & 111.8 & 44.49 \\
At most $1 *$ & 161.6 & 88.80 & 50.08 & 38.33 \\
At most 2 & 111.5 & 63.87 & 41.54 & 32.11 \\
At most 3 & 69.97 & 42.91 & 34.47 & 25.82 \\
At most 4 & 35.49 & 25.87 & 25.98 & 19.38 \\
At most 5 & 9.508 & 12.51 & 9.508 & 12.51 \\
\hline Source: Author Estimates & & &
\end{tabular}

Finally, the EGARCH model was used which gives the following results. The Table 4 summarizes the EGARCH model that is applied to the market capitalization of Karachi Stock Exchange's different sectors. 
Table 4

Results of EGARCH Mode

\begin{tabular}{|c|c|c|c|c|c|c|}
\hline & Chemical & $\begin{array}{c}\text { Construction \& } \\
\text { Material }\end{array}$ & $\begin{array}{l}\text { Finance \& } \\
\text { Insurance }\end{array}$ & Food Producers & Power \& Fuel & Textile \\
\hline \multirow{3}{*}{$\theta_{0}$} & 10.15 & 9.288 & 8.869 & 8.346 & 10.16 & 10.53 \\
\hline & -262.0 & -158.2 & -192.9 & -202.2 & -171.7 & -223.8 \\
\hline & -2.959 & -2.19 & -2.201 & -1.753 & -3.293 & -1.285 \\
\hline$\gamma_{1}$ & $(-2.641)$ & $(-2.173)$ & $(-1.021)$ & $(-2.516)$ & $(-1.249)$ & $(-1.503)$ \\
\hline \multirow[b]{2}{*}{$\gamma_{2}$} & $3.118(2.363)$ & 2.466 & 2.438 & 1.995 & 3.394 & 1.484 \\
\hline & & -1.682 & -1.019 & -2.004 & -1.215 & -1.420 \\
\hline \multirow[b]{2}{*}{$\gamma_{3}$} & 0.438 & 0.381 & 0.486 & 0.397 & 0.46 & 0.364 \\
\hline & -0.62 & -0.406 & -0.641 & -0.719 & -0.406 & -0.781 \\
\hline \multirow[b]{2}{*}{$\gamma_{4}$} & 1.027 (2.593) & 0.853 & 0.994 & 0.923 & 1.02 & 0.971 \\
\hline & & -2.964 & -3.07 & -5.042 & -1.946 & -5.089 \\
\hline$R^{2}$ & -0.022 & -0.003 & -0.018 & 0.006 & 0.0163 & -0.256 \\
\hline Adj. $R^{2}$ & -0.047 & -0.028 & -0.043 & -0.018 & -0.007 & -0.286 \\
\hline Akaike info criterion & 3.835 & 3.531 & 3.632 & 3.078 & 4.178 & 3.448 \\
\hline Schwarz criterion & 4.081 & 3.777 & 3.878 & 3.324 & 4.424 & 3.694 \\
\hline Hannan-Quinn criterion & 3.925 & 3.622 & 3.722 & 3.169 & 4.269 & 3.539 \\
\hline
\end{tabular}

The above table shows that $\gamma_{2}$ is positive and statistically significant for all of the sectors, signifying a positive leverage effect. Low $\gamma_{3}$ for all the sectors shows that there is low persistence in volatility. As anticipated earlier, the $\gamma_{4}$ coefficients are positive and statistically significant for all the sectors leading towards higher contribution of noise traders. The conditional volatility of Power and fuel and Chemical sectors are most exposed against an increase in the investor sentiment while the conditional volatility of food producers and Construction and material sectors are comparatively less affected. The reason for high conditional volatility could be the presence of big giants of the Pakistani market in these sectors. People trust more on these companies and associate a good expected return from them which cause the increase in demand of those company's stocks which ultimately increase the market capitalization of the particular sector. The market capitalization of Power and Fuel is the largest and it includes companies like K-Electric, Hub Power Company Limited, Pakistan State Oil, Sui Sothern Gas Company Limited, and etc., which are the biggest companies in Pakistan. Most of the people invest in these companies without even having any information as they have enough confidence in their names. Market capitalization of Power and Fuel and Chemical sector is PKR 1,483,529.62 million and PKR 423,496.95 million respectively. The reason for low conditional volatility in the Construction and Material and Food producer sectors could be that the major shareholding of the company lies within the family and they are less aggressive in investment decisions. Though construction and material include Cement sector which comprises of big names in the industry like Lucky Cement, Fauji Cement Company, D.G Khan Cement Company Limited etc., which performed well in the sector, but overall trading of this sector is comparatively low. The sugar and allied sector, mostly comprises of Sugar Mills, which are government owned, people rely less on Government due to lack of confidence in their offices and therefore their shares are traded less on the stock exchange.

KSE100 index is frequently traded by both the institutional and individual traders comprised of stocks of distinct companies which are banking, insurance and modarabas companies, sugar and allied industries, cement and chemical industries, power genera- 
tion and distribution, textile and other sectors.

Noise traders are the ones whose buying and selling do not stand or rely on the use of fundamental data; they are considered naïve players with a poor timing and following up the trend and usually over reacting to any good or bad news. These are the main causes that make power and fuel and chemical sectors the driving sectors that are leading the KSE and cause noise (sentiment) traders to consider them and monitor them closely. These results of the EGARCH model show that a rise in investor sentiment leads to a bigger increase in the conditional volatility of Power and Fuel and Chemical sectors. Knowing the fact that noise traders are continuously on the move to monitor the price movements and equities and listening to alternate conditions of the stock market, these findings are based on rationality, judgment and are in line with the theory of noise trade. Noise trader's abiding activity of buying and selling puts pressure on the prices and increases the volatility. Consequently, the conditional volatility of Power and Fuel and Chemical sectors are more prone to the variation in investment sentiment.

\section{Conclusion and Recommendations}

\section{Conclusion}

Different economic sectors were neglected in the earlier studies; there prime concern was on the main stock market indexes only. This research offers an understanding of the noise trader theory by examining the effects of noise traders on the conditional volatility of stock market indexes of different economic sectors of Karachi Stock Exchange. Earlier researches, which were conducted in different countries, incorporate different indexes and data which were gathered from surveys for sentiment. This study creates a sentiment proxy by using market capitalization of Karachi Stock Exchange. The data were taken from the Economic Survey of Pakistan and World Bank from the year 1972-2014.

According to the above findings, it can be noted that the investor sentiment, mainly affects the conditional volatility of the most attractive sectors of the economy as big companies of the country are listed in Power and Fuel and Chemical sectors of Pakistan and Karachi Stock Exchange. KSE100 index is the most traded and most closely monitored exchange in Pakistan, which comprises of different sectors. Overseas trading activities are also closely monitored by the traders in the KSE. Considering these factors, it can be rational to interpret that Power and Fuel and Chemical sectors could be encouraging for noise traders as they monitor trends and over react to bad and good information. Noise traders trust other traders', their activities do not rest on fundamental data and create stress on the prices which rise the volatility.

\section{Recommendation}

It can be recommended that; a number of different educational and awareness programs can be introduced to the individual investors make their financial literate. Through this process, the number of knowledgeable investors can be increased, thus the noise trader's 
impact can be reduced and efficient market can prevail. The more refined model of investment return can be made by including investor sentiment. It can also help policymakers to articulate such policies that can neutralize investor sentiment which could help to decrease volatility and ambiguity in the stock market. The study can be helpful for the Government as they come to know which sectors are more affected by investor sentiments and they can regulate the market with increased efficiency. It may also help fund or portfolio managers as they can forecast the movement of the market. Moreover, in the light of the above findings the monetary policy could have an impact on the stock market in a way that if Government policy makers increases the discount rate it could directly impact the overall stock market. An increase in discount rate could weaken the intensity of investor sentiment as the investors may shift their investments to less riskier financial assets and more secured returns and vice versa. Furthermore, the fiscal policy could also have an impact on the stock market in such a way that if taxation authorities increases the tax rate, this will reduce the ability of the company to offer more dividends which could adversely affect the capacity of the noise traders to create volatility. Also, the Securities and Exchange Commission of Pakistan (SECP) can make the data available in the easiest format for ready reference to the common investors, which can reduce the impact of investor sentiment on the stock market as investors could have more fundamental knowledge which might lead to an efficient market.

For further research, it is recommended that the influence of investor sentiment on individual stock within the particular sector should be investigated so that more detailed and precise knowledge about the investor sentiments will be established. An interesting extension of this research would be to study the impact of business cycle stages on investor sentiment and to see how this affects the stock market volatility for different sectors. Further, the researchers could also extend this research by doing a cross-country analysis by involving data from more markets or regional and economic groups and can be used to compare the outcomes of two or more countries. Additionally, similar research can also be conducted on other indexes i.e. KMI30, LSE25, ISE10, so that the more indepth analysis could be done to generalize this research to overall Pakistani market. 


\section{References}

Beaumont, R., van Daele, M., Frijns, B., Lehnert, T., \& Muller, A. (2008). Investor sentiment, mutual fund flows and its impact on returns and volatility. Managerial Finance, 34(11), 772-785.

Białkowski, J., Etebari, A., \& Wisniewski, T. P. (2012). Fast profits: Investor sentiment and stock returns during Ramadan. Journal of Banking E Finance, 36(3), 835-845.

Bollerslev, T. (1986). Generalized autoregressive conditional heteroskedasticity. Journal of Econometrics, 31(3), 307-327.

De Long, J. B., Shleifer, A., Summers, L. H., \& Waldmann, R. J. (1990). Noise trader risk in financial markets. Journal of Political Economy, 98(4), 703-738.

Engle, R. (2001). Garch 101: The use of ARCH/GARCH models in applied econometrics. Journal of Economic Perspectives, 15(4), 157-168.

Engle, R. F. (1982). Autoregressive conditional heteroscedasticity with estimates of the variance of United Kingdom inflation. Econometrica: Journal of the Econometric Society, 987-1007.

Finter, P., Niessen-Ruenzi, A., \& Ruenzi, S. (2012). The impact of investor sentiment on the German stock market. Zeitschrift für Betriebswirtschaft, 82(2), 133-163.

$\mathrm{Hu}, \mathrm{C}$., \& Wang, Y. (2013). Noise trading and stock returns: Evidence from China. China Finance Review International, 3(3), 301-315.

Kholdy, S., \& Sohrabian, A. (2014). Noise traders and the rational investors: A comparison of the 1990s and the 2000s. Journal of Economic Studies, 41(6), 849-862.

Lee, W. Y., Jiang, C. X., \& Indro, D. C. (2002). Stock market volatility, excess returns, and the role of investor sentiment. Journal of Banking $\mathcal{E}$ Finance, 26(12), 2277-2299.

Li, J. (2015). The asymmetric effects of investor sentiment and monetary policy on stock prices. Applied Economics, 47(24), 2514-2522.

Lux, T. (2011). Sentiment dynamics and stock returns: The case of the German stock market. Empirical Economics, 41(3), 663-679.

Malkiel, B. G. (1991). Efficient market hypothesis. UK: Palgrave Macmillan.

Nelson, D. B. (1991). Conditional heteroskedasticity in asset returns: A new approach. Econometrica: Journal of the Econometric Society, 347-370.

Peng, C.-L., Lai, K.-L., Chen, M.-L., \& Wei, A.-P. (2015). Investor sentiment, customer satisfaction and stock returns. European Journal of Marketing, 49(5/6), 827-850.

Qiang, Z., \& Shu-e, Y. (2009). Noise trading, investor sentiment volatility, and stock returns. Systems Engineering-Theory \& Practice, 29(3), 40-47.

Raza, S. A. (2015). Foreign direct investment, workers' remittances and private saving in Pakistan: An ARDL bound testing approach. Journal of Business Economics and Management, 16(6), 1216-1234.

Raza, S. A., \& Jawaid, S. T. (2014). Foreign capital inflows, economic growth and stock market capitalization in Asian countries: An ARDL bound testing approach. Quality $\mathcal{E}$ Quantity, 48(1), 375-385.

Raza, S. A., Jawaid, S. T., Afshan, S., \& Karim, M. Z. A. (2015). Is stock market sensitive to foreign capital inflows and economic growth? Evidence from Pakistan. Journal of Chinese Economic and Foreign Trade Studies, 8(3), 142-164. 
Raza, S. A., Jawaid, S. T., Arif, I., \& Qazi, F. (2011). Validity of capital asset pricing model in Pakistan: Evidence from Karachi Stock Exchange. African Journal of Business Management, 5(32), 12598-12605.

Sayim, M., Morris, P. D., \& Rahman, H. (2013). The effect of us individual investor sentiment on industry-specific stock returns and volatility. Review of Behavioural Finance, 5(1), 58-76.

Simões Vieira, E. (2011). Investor sentiment and the market reaction to dividend news: European evidence. Managerial Finance, 37(12), 1213-1245.

Szu, W.-M., \& Yang, W.-R. (2015). Influence of individual investor sentiment on Taiwan option prices during 2007-2010 financial crisis. Managerial Finance, 41(5), 437-464.

Uygur, U., \& Taş, O. (2014). The impacts of investor sentiment on different economic sectors: Evidence from Istanbul stock exchange. Borsa Istanbul Review, 14(4), 236241.

Verma, R., \& Verma, P. (2007). Noise trading and stock market volatility. Journal of Multinational Financial Management, 17(3), 231-243.

Wang, Y.-M., Li, C.-A., \& Lin, C.-F. (2009). The impact of investor sentiment on the futures market: Evidence from the Taiwan futures exchange. International Research Journal of Finance and Economics, 28, 134-151. 